\title{
Una osadía de Sarmiento. Autobiografía y novela en Recuerdos de provincia
}

Recibido: noviembre 2018 Aprobado: agosto 2019

\begin{abstract}
Resumen
Las circunstancias de la escritura y la publicación de Recuerdos de provincia, en diciembre de 1850, son más o menos conocidas. Sin embargo, el paso del tiempo ha tendido a hacer olvidar o a diluir el riesgo que implicó para Sarmiento escribir y publicar su autobiografía. En este artículo, a partir de diferentes abordajes teóricos del género autobiográfico (entre otros los de Judith Butler o Jean Starobinski), se analiza dónde radicaba específicamente el riesgo que corrió Sarmiento al escribir y publicar su autobiografía. En igual sentido, a partir de ciertas afirmaciones de Lionel Gossman sobre las Confesiones de Rousseau, se propone además que ese riesgo implicaba, muy especialmente, la puesta en crisis de lo que en ese momento se consideraba con derecho a ser escrito y publicado y qué no. Una hipótesis central, entonces, es que Recuerdos de provincia buscó, acaso impensadamente, romper con lo que se consideraba como escribible y publicable. Finalmente, en relación estrecha con lo anterior, y a propósito de ciertas ideas de Jacques Rancière sobre el "régimen estético", se elucubra sobre la posibilidad de que estas características del texto se vinculen con la presencia en él de lo novelesco, y se propone pensar Recuerdos de provincia como una entonación de la Bildungsroman, género central de la novela en el siglo XIX.
\end{abstract}

PALABRAS CLAVE: Autobiografía, novela, Sarmiento, Alberdi.

\section{A daring of Sarmiento. Autobiography and novel in Recuerdos de provincia}

\begin{abstract}
The circumstances of the writing and the publication of Recuerdos de provincia, in December of 1850, are more or less known. However, the passage of time has tended to make one forgetful of the risk that Sarmiento entailed in writing and publishing his
\end{abstract}


autobiography. In this article, drawing from different theoretical approaches to the autobiographical genre (among others, those of Judith Butler and Jean Starobinski), it is analyzed how that particular risk took place. Likewise, based on certain statements by Lionel Gossman on the Confessions of Rousseau, it is also proposed that this risk implied, very markedly, the putting into crisis of what, at that time, was considered to be proper to be written and published and what was not. A central hypothesis, then, is that Recuerdos de provincia sought, perhaps unthinkingly, to break with what in its epoch was considered as writable and publishable. Finally, in relation to certain ideas of Jacques Rancière on the "aesthetic regime", we consider the possibility that these characteristics of the text are linked to the presence of the novelistic, and then it is proposed to think of Recuerdos de provincia as an intonation of the Bildungsroman, a capital genre of the novel in the nineteenth century.

KEYWORDS: Autobiography, novel, Sarmiento, Alberdi

\section{Uma ousadia de Sarmiento. Autobiografia e romance em Recuerdos de provincia}

\section{Resumo}

As circunstâncias da redação e publicação de Recuerdos de Provincia, em dezembro de 1850 , são mais ou menos conhecidas. No entanto, a passagem do tempo tendeu a fazer esquecer o risco em que Sarmiento incorria ao escrever e publicar sua autobiografia. Neste artigo, a partir de diferentes abordagens teóricas do gênero autobiográfico (entre outras, as de Judith Butler e Jean Starobinski), analisa-se a especifidade do risco que Sarmiento correu ao escrever e publicar sua autobiografia. Do mesmo modo, com base em certas afirmações de Lionel Gossman sobre as Confissões de Rousseau, propõese também que esse risco implicou, muito particularmente, pôr em crise o que então se considerava legítimo ser escrito e publicado e o que não era. Uma hipótese central, então, é que Recuerdos de Provincia buscou, talvez de maneira impensada, romper com o que era, à época, considerado escrevível e publicável. Por fim, em relação a certas ideias de Jacques Rancière sobre o "regime estético", considera-se a possibilidade de que essas características do texto estejam ligadas à presença nele do romanesco, e se propõe pensar Recuerdos de Provincia como uma entonação do Bildungsroman, um gênero capital do romance no século XIX.

PALABRAS CHAVE: Autobiografia, romance, Sarmiento, Alberdi

Luego de sus andanzas por Europa, África y América, instalado otra vez en Chile, en 1848 Domingo Faustino Sarmiento le remitió una carta al coronel José Santos Ramírez en la que afirmaba: "Yo me apresto a entrar en campaña". Según Ricardo Rojas, Sarmiento no aludía allí a la disposición para algún tipo de acción militar sino para realizar, lejos de su patria, una campaña periodística inclaudicable contra el gobierno de Juan Manuel de Rosas. Más allá del deslinde propuesto por Rojas, lo cierto es que en 1848 apareció La Tribuna y en 1849 el más famoso La Crónica. Un objetivo principal de la escritura de Sarmiento en esos periódicos era atacar y desprestigiar el rosismo. En La Crónica, por ejemplo, a propósito de la soberanía sobre el estrecho de Magallanes, escribió a favor de los derechos chilenos y en contra de las aspiraciones de Rosas sobre ese territorio. Esperablemente, la acusación de traidor a la patria no tardó en ser pronunciada. 
La carta a Ramírez, que este remitió a Rosas seis meses después de haberla recibido (Rojas, 1945: 348) y que fue difundida profusamente por el territorio argentino, la defensa de Chile en la disputa por la soberanía sobre el estrecho de Magallanes y varios de los artículos publicados en La Crónica enojaron, habría que decir que inevitablemente, al gobernador de la provincia de Buenos Aires. Ese enojo se advierte, en especial, en la fundación, en Mendoza, del periódico La Ilustración Argentina, que se ocupó de injuriar sistemáticamente a Sarmiento, en las dos notas que durante 1849 le fueron remitidas al gobierno chileno solicitando su extradición, una en abril y otra en julio, y en las varias páginas que, en el Mensaje que en diciembre de 1849 Rosas presentó ante la Legislatura, le estaban dedicadas. Allí, entre otros epítetos, Sarmiento era mencionado como "el aleve conspirador Sarmiento", "el rebelde Sarmiento" o "el traidor Sarmiento” (Rojas, 1945: 359).

Esos son sumariamente algunos antecedentes de la escritura y de la inmediata publicación, en diciembre de 1850, de Recuerdos de provincia. Esos y otros hechos le permitieron a Sarmiento, tal como se advierte en las páginas liminares de su autobiografía, disponer con habilidad de unas circunstancias que lo colocaban en el lugar de alguien que podía incurrir legítimamente en la escritura autobiográfica para defenderse de ciertas acusaciones, limpiar su nombre y exponer, frente a la palabra injuriante del otro, su verdad. Sarmiento, entonces, supone o conjetura una demanda de discurso autobiográfico que, presuroso, se apresta a satisfacer.

\section{El derecho a la autobiografía}

La escritura autobiográfica fue considerada varias veces como respuesta a una acusación. Ángel Loureiro, por ejemplo, emparienta el "acto autobiográfico" con el "contexto judicial" (2006: 29). Judith Butler, por su parte, en Darcuenta de símismo, revisa y discute la aseveración de Friedrich Nietzsche en La genealogía de la moral según la cual "damos cuenta de nosotros mismos únicamente porque se nos interpela en cuanto seres a quienes un sistema de justicia y castigo ha puesto en la obligación de rendir cuentas" (2009: 35). En ambos casos, además, el abordaje de lo autobiográfico hace especial énfasis no tanto en el yo como en la relación de ese yo con un otro; es decir, se elucubra sobre la responsividad de lo autobiográfico y sobre su índole relacional. Entonces, desde esta perspectiva, se postula que aquel que da cuenta de sí lo hace porque es un individuo acusado, acaso culpable. Al respecto, Sarmiento aparece en Recuerdos de provincia como alguien que fuerza el montaje de esa escena judicial; es decir, no como alguien que, obligadamente, debe hablar de sí porque lo han conminado a "rendir cuentas", porque es culpable, sino como alguien que pergeña una excusa que lo habilita a hacerlo. Por lo tanto, la afirmación acerca de que su autobiografía era "una consecuencia inevitable de los epítetos de infame, protervo, malvado, que me prodiga el gobierno de Buenos Aires" (2001: 16) debería ser considerada como una suerte de petición de principios. Su libro distaba mucho de ser uno inevitable. Por el contrario, varios de aquellos a los que creía su principal auditorio (los "compatriotas" a los que se dirige en el arranque de Recuerdos de provincia) percibieron en esa decisión de hablar abundantemente de sí poco más que el testimonio de una desvergüenza y de una autoindulgencia irreprimibles, algo que debería haber evitado.

No era esa la primera vez que Sarmiento aprovechaba circunstancias adversas a su persona para ejercitarse en el género autobiográfico. Esta es una estrategia que ya había puesto en práctica siete años antes. Durante 1843, lo ocupó una polémica con Domingo S. Godoy. A ciertas acusaciones o difamaciones de este último -por ejemplo, la de haber robado el dinero juntado en Chile para socorrer a los fugitivos de Rodeo del Medio-, respondió con diversos escritos y una presentación ante los tribunales chilenos por haber sido calumniado. Sarmiento finalmente retiró su presentación 
judicial ante la promesa de Godoy de no volver a infamarlo. La secuela de esas escaramuzas con Godoy fue la publicación de un folleto de naturaleza autobiográfica titulado Mi defensa. ${ }^{1}$ Allí, en uno de los primeros apartados ("Mi infancia"), Sarmiento conjetura en el otro una necesidad de discurso autobiográfico que él se dispone, solícito, a colmar: "voy ahora a cumplir con lo que el deber y la sociedad me imponen. Vean quién es el hombre que tantas importunidades causa, vean mis títulos" (1885: 16). Aquí, pues, no es Sarmiento quien decide escribir un texto autobiográfico, sino que -de acuerdo a cómo plantea o dispone la situación- son otros los que le imponen una tarea a la que no se puede rehusar. Pero como bien lo señaló Rojas, el contenido de Mi defensa no se agota en absoluto en una respuesta a las acusaciones de Godoy. Esa respuesta resulta la pretexto para "presentar a Chile su autobiografía" (1945: 174). Mi defensa y Recuerdos de provincia difieren en varios aspectos; sin embargo, en ambos se asiste al armado estratégico de una instancia primera de petición de escritura autobiográfica que acicatea la escritura del yo. En ese específico sentido Midefensa sí es un antecedente de Recuerdos de provincia. ${ }^{2}$

En Recuerdos de provincia, la limpieza del nombre propio no solo permite la reivindicación de un pasado sino también, de manera más velada, la postulación de que ese pasado -es decir, de lo realizado hasta el momento de la publicación- le otorgaba al autobiógrafo credenciales como para ocupar un lugar de importancia en la historia futura de su patria. De hecho, según aseguran entre otros los biógrafos José Campobassi y Allison Williams Bunkley, más o menos por la época de la publicación de Recuerdos de provincia distribuyó en Chile un retrato suyo acompañado de un epígrafe que era la nítida y sintética expresión de su máxima apetencia (lo no dicho, o dicho entre líneas, en Recuerdos de provincia): "D. F. Sarmiento, futuro presidente de la República".3

$\mathrm{Al}$ respecto, en un apartado de las Cartas quillotanas al que más adelante me referiré con más detalle, Juan Bautista Alberdi denuncia ese propósito electoralista: "su biografía de usted no es un simple trabajo de vanidad, sino el medio muy usado y muy conocido en política de formar la candidatura de su nombre para ocupar una altura cuyo anhelo legítimo, por otra parte, le hace agitador incansable" (2005: 112). Para Alberdi Recuerdos de provincia debía ser leído, antes que nada, como lo que en inglés se denomina campaing biography: una biografía que forma parte de la publicidad que acompaña la candidatura de alguien a algún cargo político, en especial a la presidencia. Esa, acaso, era la "campaña" a la que Sarmiento se aprestaba a entrar en 1848: una campaña electoral. ${ }^{4}$

\footnotetext{
1 Los pormenores de la polémica y de la publicación de Mi defensa pueden leerse en Rojas (1945) y Williams Bunkley (1966).

2 En otros aspectos difieren bastante: mientras que el de Mi defensa es “un agónico héroe desarraigado" (Altamirano y Sarlo, 1997: 107), el de Recuerdos de provincia es alguien que puede exhibir un linaje, una prosapia. Si el autobiógrafo de Mi defensa es únicamente un self-made man, el de Recuerdos de provincia es, además, el descendiente o heredero de una serie de varones ilustres que tuvieron mucho que ver en los destinos de la patria.

3 Sobre la "clave política del texto" véase, entre otros, Altamirano y Sarlo (1997). En uno de los trabajos más recientes sobre Recuerdos de provincia, Hernán Pas (2015) analiza el carácter publicitario -el foco puesto en el porvenir, para decirlo de otro modo- de la autobiografía de Sarmiento.

4 Según el historiador Scott S. Casper (1999) las biografías de campaña fueron muy comunes en Estados Unidos en el siglo XIX, y es muy posible que a Sarmiento el fenómeno no le haya pasado inadvertido durante su estadía en ese país en 1847. De hecho, en la carta “Estados Unidos" de Viajes por Europa, África y América da cuenta, con admiración, de la importante cantidad de biografías que se habían publicado en ese país entre 1830 y 1842: "ciento seis obras originales sobre biografía". Nathaniel Hawthorne, por ejemplo, en 1852 escribió la biografía de campaña de su amigo Franklin Pierce, cuyo título fue, sencillamente Life of Franklin Pierce. En 1851, Sarmiento escribió Candidato a la presidencia de Chile, D. Manuel Montt, una biografía que fue parte de la campaña de Montt para acceder a la presidencia. Muchos años después, Lucio V. Mansilla (2001) escribirá que Sarmiento no aceptaba que él y otros habían hecho que llegara a la presidencia, sino que, equivocadamente, estaba seguro de que era su biografía de Lincoln (publicada en 1865) la que le había abierto el camino hacia ese cargo. Es decir, Mansilla lee Vida de Lincoln como una suerte de desviada biografía de campaña.
} 
En una carta que le remitió a Vicente Fidel López en diciembre de 1849 puede leerse:

¿Ha notado usted una cosa singular? Y es que he conquistado en Chile el derecho de hablar de mí mismo, de ocuparme de mis negocios y de mi reputación, con el mismo desenfado de Rosas en la Gaceta. Ya saben que este es mi defecto, y me lo toleran. Preparo un librote titulado Recuerdos de provincia o cosa parecida, en que hago con el mismo candor que Lamartine mi panegírico. Y lo protesto amigo que el ridículo ha de venir a estrellarse contra tantas cosas buenas, y dignas de ser narradas, que tendrán de grado o por fuerza que perdonarme la osadía. (1998: 140, énfasis mío)

En principio, Sarmiento aquí parece estar muy seguro de gozar del "derecho de hablar de sí mismo". No obstante, en el mismo párrafo, atenúa esa seguridad: la publicación de Recuerdos de provincia -es decir, de un texto en el que, principalmente, hablará de sí mismo- será una "osadía". En igual sentido, en el prólogo a Recuerdos de provincia, se detecta el temor a que su incursión en la escritura autobiográfica generara entre los lectores, antes que otra cosa, el "desdén" y la "crítica". Era más que probable que no se lo perdonaran, que no se lo toleraran. ${ }^{5}$

Y no se equivocaba. En términos generales, Recuerdos de provincia no fue bien acogido por sus contemporáneos. Como ejemplo de esa recepción negativa, Ana María Barrenechea cita una carta de Félix Frías a Juan María Gutiérrez en la que aquél asegura: "He leído algunas páginas de Recuerdos de provincia y sus cartas publicadas por La Gaceta Mercantil. [...] Todo esto no está bien y le daña, a los ojos, sobre todo, de los que no saben apreciar la bondad de su carácter como sus amigos inmediatos" (Barrenechea, 1988: 409). ${ }^{6}$

¿Pero qué es lo que, para usar las palabras de Frías, no está bien en Recuerdos de provincia? ¿Qué es lo que impacienta o escandaliza a los contemporáneos de la publicación de esta autobiografía? ¿Qué es lo que no se tolera? ¿A qué se atrevió Sarmiento?

En "Condiciones y límites de la autobiografía", Georges Gusdorf asegura que la escritura autobiográfica implica el convencimiento de que "cada hombre es importante para el mundo, cada vida y cada muerte" y, complementariamente, que "el testimonio que cada uno se da de sí mismo enriquece el patrimonio común de la cultura" (1991: 10). En las páginas de Recuerdos de provincia se advierte, siquiera tímidamente, ese convencimiento: las vidas narradas en este libro son, para su autor, vidas con derecho a ser narradas, vidas importantes para el mundo, para usar los términos de Gusdorf (recuérdese, en la carta a López, la aseveración de que el libro estaría colmado de "cosas dignas de ser narradas"). De que un convencimiento tal no era aceptado ni mucho menos, hacia 1850 , es testimonio cierta zona de la tercera quillotana a la que ya me referí brevemente más arriba. Allí, Alberdi no solo determina la inutilidad del libro -"Historiándose a sí mismo no ha podido aprender más de lo que usted sabe. Ese trabajo no es un servicio hecho a la República Argentina, y dudo que lo sea para usted mismo" (2005: 111-112)-, sino

5 Ello explica también, entre otras cosas, la presencia de una de las citas de autoridad que, como epígrafe, abre Recuerdos de provincia: "Decir de sí menos de lo que hay, es necedad y no modestia; tenerse en menos de lo que uno vale, es cobardía y pusilanimidad, según Aristóteles”. Aquí Sarmiento quiere advertirles a sus lectores que nada menos que Montaigne y Aristóteles habilitaban su empresa autobiográfica. El otro epígrafe, el de Shakespeare (el adjudicado a Hamlet y no a Macbeth: "Es este un cuento que, con aspavientos y gritos, refiere un loco, y que no significa nada"), acaso está ahí para restarle importancia al libro, para minimizar su relevancia: se trata, meramente, de algo dicho por un loco, que no significa nada. Es decir, habría que leerlo como una forma no ortodoxa de captatio benevolentiae.

6 En la misma línea, José Campobassi asegura: “El confesado propósito político de Sarmiento al escribir Recuerdos de provincia hizo que muchos amigos del exilio le pidieran que se abstuviera de editarlo, por creer que el libro podría dañar su reputación" (1975, I: 291). 
que también dictamina el descaro o la desvergüenza de Sarmiento por haberse atrevido a escribir no solo sobre su vida sino también sobre la de "su parentela" o "sus criados". Consigna un indignado Alberdi:

Es el primer ejemplo que se ofrece en nuestro país, tan abundante en hombres notables, de un republicano que publica doscientas páginas y un árbol genealógico para referir su vida, la de todos los individuos de su parentela y hasta la de sus criados. (2005: 112)

Por un lado, en estas afirmaciones Alberdi insinúa que escribir una autobiografía resulta un acto de vanidad y de exhibicionismo que entra en contrariedad con un republicanismo austero que, entre otras características, tendría la de cierta reticencia a los discursos sobre el yo. ${ }^{7} \mathrm{Al}$ mismo tiempo, Alberdi apunta otra certeza: la de que hay vidas que no merecen ser contadas, vidas que no son, y acá cito el texto de Gusdorf, "importantes para el mundo": en este caso, las de la parentela y los criados de Sarmiento y también, según entiendo, la del propio autobiógrafo. Para Alberdi, Recuerdos de provincia era un libro supernumerario, inútil. Un libro que registra cosas que no era necesario contar: vidas indignas de ser contadas, vidas insignificantes, vidas sin "derecho a la biografía" (Lotman, 2006). ${ }^{8}$ Desde la perspectiva de Alberdi, Recuerdos de provincia no enriquecería en absoluto "el patrimonio común de la cultura".

En un trabajo minucioso sobre la relación entre las anécdotas y la historia, Lionel Gossman refiere el desinterés de Voltaire por aquellas. Gossman explica que ese desinterés se vinculaba al hecho de que, para Voltaire, la historia no debía reducirse al relato de las vidas de los reyes y debía ocuparse prioritariamente de "las naciones y las civilizaciones". Pero también asegura que ese "juicio negativo" sobre las anécdotas se asociaba a otra cuestión. Ese desprecio, afirma, estaba determinado por la misma

estética (y política) clásica y fundamentalmente conservadora que algo después llevará a los editores de L'Année littéraire a condenar las Confesiones de Rousseau como un acto de arrogancia y presunción literaria. "¿Dónde estaríamos ahora", protestaban en 1782 , "si cada uno se arrogara el derecho a escribir e imprimir todo lo que le concerniera personalmente y que le resultara placentero contar?". Es difícil no leer este indignado rechazo al reclamo por parte de Rousseau de que las más humildes anécdotas concernientes a la vida personal de un oscuro niño casi huérfano (no obstante uno que se volvería un escritor famoso) son dignas de interés como la expresión de nada más que un clásico (y conservador) deseo de control del conocimiento de la historia y de preservar la jerarquía, tanto en la historia como en la sociedad, mediante la imposición de qué debería contar como importante y digno de importancia y qué no. (Gossman, 2003: 154, traducción mía)

En este sentido, razono que el también "indignado rechazo" de Alberdi ante la publicación de Recuerdos de provincia echa en gran medida sus raíces en aquello a lo que alude Gossman para explicar el desdén de L'Année littéraire a las Confesiones de Rousseau (un texto al que, como se recordará, Sarmiento se refiere en su autobiografía): la voluntad de preservar el control y las jerarquías "tanto en la historia como en la sociedad". Si "Rivadavia, Monteagudo, Paso, Alvear y cien héroes argentinos están sin biografía, y la misma república, que es toda gloria y heroicidad, está sin historia" (2005: 112), era

7 Me ocupé de la cuestión de la vanidad en las autobiografías de Sarmiento y Alberdi en Fontana (2015).

8 Un ejemplo de esto es la referencia, que hace Sarmiento en el capítulo “Mi educación”, a las vidas de sus compañeros de juegos infantiles: Barrilito, Piojito, Chuúa, Velita, el Guacho Riberos y Capotito. Ya en la preferencia por los apodos, en los que el diminutivo prevalece, se advierte la predilección o el gusto sarmientinos por lo menor, por las vidas acaso insignificantes o inútiles de ser narradas en términos de una escritura solo interesada por la relevancia histórica o ejemplar de una vida. Sobre las burlas que recibió Sarmiento a lo largo de su vida con relación a su vínculo con Piojito y el lugar que este ocupa en Recuerdos de Provincia véase Roman (2010). 
desde todo punto de vista inaceptable que Sarmiento se hubiese atrevido -hubiese osado- a escribir y, peor aún, a imprimir su autobiografía. Alberdi parece insinuar también que incluso si esas biografías -las de Rivadavia, Paso o Alvear- hubiesen existido, Sarmiento tampoco habría gozado del derecho a publicar la suya.

Afirma Gusdorf: "El sujeto que se toma a sí mismo cono objeto invierte el movimiento natural de la atención; al hacer esto, parece estar violando ciertas prohibiciones secretas de la naturaleza humana" (1991: 11). Al respecto, habría también que decir que los contemporáneos de Sarmiento -y, entre ellos, por supuesto, especialmente Alberdi, pero también Frías en la carta mencionada anteriormente- parecen haber detectado, no sin pocas prevenciones, ese acto contra natura en el que habría incurrido Sarmiento al escribir e imprimir su autobiografía.

En lo que quiero hacer hincapié puntualmente aquí es en algo que el paso del tiempo ha tendido, creo, ha tendido a diluir; algo en lo que no se repara lo suficiente: la escritura y la publicación de Recuerdos de provincia implicaron una transgresión de aquello que, por esos años, el sentido común aseguraba que podía ser escrito e impreso. Se trata, pues, de una escritura atrevida, temeraria. En consecuencia, me interesa ver en Sarmiento, a escala sudamericana, a alguien que, como décadas antes Rousseau en Europa, se atrevió a ir contra las jerarquías de la historia y el consenso acerca de lo que podía o no podía escribirse y publicarse. Por esa razón, leer en Recuerdos de provincia una mera evidencia más del egotismo de Sarmiento -"monumento de egotismo", llamó Manuel Gálvez (1962) a Recuerdos de provincia- es reducir injustamente a una interpretación psicológica o psicologizante la densidad y la relevancia del acontecimiento literario que fue en 1850 la aparición de este libro autobiográfico.

Lo anterior podría decirse de otra manera. Afirma Jean Starobinski que la escritura autobiográfica presupone ciertas condiciones de posibilidad que aparecen en primer lugar como condiciones ideológicas o culturales: "importancia de la experiencia personal y oportunidad de ofrecer el relato sincero de esa experiencia a los demás" (2008: 82). Estas condiciones establecen la legitimidad del yo y autorizan al sujeto del discurso a tomar como tema su existencia pasada. Ese sería, pues, el horizonte de expectativas de la autobiografía. En el caso de Sarmiento, antes que suponer o dar por descontadas esas "condiciones de posibilidad", la escritura y publicación de Recuerdos de provincia involucran su voluntad de imponerlas y, acaso más ambiciosamente, de fundarlas. Sarmiento acomete la escritura de su autobiografía cuando aún esas condiciones no eran un a priori que sus contemporáneos consentían o toleraban. ${ }^{9}$ De ahí -insisto- el carácter disruptivo de su escritura autobiográfica: una verdadera osadía.

\section{Vidas de novela}

Ese carácter disruptivo de Recuerdos de provincia, que desde la perspectiva de Alberdi radicaría en que allí se narra lo que no debería narrarse -en que allí no se respetan ni las jerarquías de la historia ni las de la sociedad- podría vincularse con otro género crucial del siglo XIX: la novela.

9 Muy diferente será lo que ocurra desde la década de 1870 en adelante. En la primera mitad de la década del 70, por ejemplo, Alberdi, quien en la década del so se mostraba muy refractario a hablar de sí -“Rara vez o nunca hablo de mí. Tengo por ridículo el yo, como dice Pascal” (2005: 117), escribió en la cuarta quillotana-, se decide a escribir, y en un caso a publicar, dos textos autobiográficos: Palabras de un ausente y Mi vida privada. Luego, desde 188o, y de allí en más, comienza a proliferar la literatura autobiográfica. Desde entonces, lo autobiográfico, el memorialismo y el recuerdo son prácticas escriturarias legitimadas, permitidas y hasta esperables (Miguel Cané, Martín García Merou, Eduardo Wilde o Lucio V. Mansilla, entre otros, publican sendos textos de índole autobiográfica desde 188o en adelante). Me ocupé de estas cuestiones en Fontana (2010). 
La interrogación por la presencia de lo novelístico en la escritura de Sarmiento fue formulada más de una vez. Me detendré solo en dos. En Historia de Sarmiento, de 1911, Lugones asegura que "Sarmiento subordinó sus dotes de escritor a estos rasgos de periodista" (1911:151), para enseguida agregar: "En otro ambiente, y con otra misión, habría hecho novela" (151). Para Lugones, Sarmiento no pudo ser un novelista; pero, según entiendo, en virtud de la plena conciencia que tenía de su "misión genial", tampoco tuvo interés en serlo. ${ }^{10}$ Por lo demás, Lugones propone que el lugar en el que se realiza de manera desviada la "vocación de novelista" de Sarmiento es en su escritura biográfica. Es allí donde se puede entrever a un hipotético Sarmiento novelista:

De aquel estilo fragmentario, proviene su característica más saliente como autor de libros. Es el escritor de los trozos selectos. Imposible encontrar en su vasta obra una pieza completa. Esta peculiaridad, unida a su vocación de novelista, que no puede satisfacer porque necesita todas sus letras para la grande obra de hacer país, determina su predilección biográfica. Las "vidas" constituyen una especialidad de su literatura. (1911: 158-159)

Habría que decir, entonces, que entre la descomunal producción textual de Sarmiento la biografía -y también la autobiografía, que en las páginas liminares de Recuerdos de provincia casi no deslinda de la biografía- se recorta como la novela de la inmediatez, de la premura. ${ }^{11}$ Para Lugones, Facundo es, entre otras cosas, "nuestra gran novela política" y, en el mismo sentido, afirma que los esbozos biográficos de Baigorria, Sandes y Gauna que Sarmiento inserta en el Itinerario del primer cuerpo de ejército de Buenos Aires, de 1863, "poseen el interés pintoresco de la novela de aventuras" (1911: 159). Muchas décadas después, Ricardo Piglia se preguntó por la matriz novelística de Facundo y concluyó que ese libro es "una prosa-novela, una máquina de novelar, el museo de la novela futura" (1998: 27). Se trataría, según Piglia, de un uso político del género. ${ }^{12}$

En esta línea, es pertinente interrogarse también acerca de qué hay de novelesco en Recuerdos de provincia. ${ }^{13}$ En principio, en esta autobiografía accedemos a la formación del autobiógrafo. Una formación que se inicia en la niñez con el estímulo paterno de la lectura y la asistencia a la escuela dirigida por don José Ignacio y don José Jenaro Rodríguez, y que tiene como cierre el contacto con la "escogida biblioteca de autores modernos" de Manuel Quiroga Rosas y con las conversaciones con este y con otros doctores como Aberastain, Cortínez y Rodríguez. Sobre esas lecturas y esas relaciones dice Sarmiento, a manera de conclusión:

[...] empecé a sentir que mi pensamiento propio, espejo reflector hasta entonces de las ideas ajenas, empezaba a moverse y a querer marchar. Todas mis ideas se fijaron clara y distintamente, disipándose las sombras y vacilaciones frecuentes en la juventud que comienza, llenos ya los vacíos que las lecturas desordenadas de veinte años habían podido dejar. (2001: 148)

10 Lo que no implica decir que Sarmiento no estuviera interesado en la novela como género; por el contrario, Lugones recuerda que Sarmiento “atribuía gran importancia civilizadora a la lectura de novelas. 'Las novelas han educado a la mayoría de las naciones”" (1911: 159).

11 Entre textos largos y breves, Sarmiento escribió, según el cómputo de José Campobassi, más de sesenta biografías. 12 En una carta que en 1849 le dirigió a Alberdi, Esteban Echeverría se despacha sobre las supuestas deficiencias de la escritura sarmientina: “¿Qué cosa ha escrito él que no sean cuentos y novelas según su propia confesión? ¿Dónde está en sus obras la fuerza de raciocinio y las concepciones profundas? Yo no veo en ellas más que lucubraciones fantásticas, descripciones y raudal de cháchara infecunda” (1900: 793-794, énfasis mío). Además, en una carta previa del mismo año, Echeverría se refiere a Sarmiento como alguien "poseído por la manía del cuento y de la anécdota" (1900: 789, énfasis mío). Novelas, anécdotas: esos materiales o géneros son, junto a otros más, los elementos que incomodan en la escritura de Sarmiento.

13 Esta pregunta ya se la realizó hace años Noé Jitrik (1997) cuando se refirió al “fuerte desplazamiento hacia la narración" que caracterizaría a Recuerdos de provincia. 
En ese momento, 1838, Sarmiento tiene 27 años. El corolario de esa educación será el éxito obtenido por la publicación, tres años después, de un artículo en el periódico $E l$ Mercurio, firmado con el seudónimo "Un teniente de artillería de Chacabuco", suerte de epifanía intelectual gracias a la cual puede darse cuenta de que su "vocación" (2001: 167) era ser escritor. Allí termina la autobiografía, los recuerdos de provincia: lo que viene después - por ejemplo, la lista de publicaciones realizadas- es consecuencia de lo anterior. ${ }^{14}$ En razón de esto, podría concluirse en que Recuerdos de provincia es una Bildungsroman, una novela de educación o formación. $\mathrm{O}$, si se prefiere, una protonovela de formación. ${ }^{15}$ En efecto, en ese libro asistimos al desarrollo de un sujeto "a través de sucesivas experiencias que van afectando su posición ante sí mismo, y ante el mundo y las cosas" (De Diego, 1998: 7).

Jacques Rancière acuñó el concepto de "régimen estético" para referirse a una etapa del arte cuya emergencia a fines del siglo XVIII implicó

la caída del sistema de coerciones y jerarquías que constituía el régimen representacional del arte. Significó el desprecio por los rangos de temas, géneros y formas de expresión que separaban a los objetos dignos de los indignos de entrar en el reino del arte, o a los géneros altos de los bajos. Implicó una infinita apertura del campo del arte y, en última instancia, la supresión de la frontera entre arte y no-arte, entre creación artística y vida anónima. (2006: XX)

Esa "caída" se advierte en especial, en el siglo XIX, en la novela. Rancière, en efecto, ha ejemplificado qué es el régimen estético en análisis de novelas fundamentales de ese siglo como Notre-Dame de Paris, de Victor Hugo, o Madame Bovary, de Gustave Flaubert. ${ }^{16}$ Discurrir sobre la presencia de lo novelesco en Recuerdos de provincia

14 Recuerdos de provincia es, por tanto, la historia de una vocación de escritor, como se afirma frecuentemente sobre la novela En busca del tiempo perdido, de Marcel Proust (Genette, 1989: 282).

15 Sobre la novela de formación existen, entre muchos otros, el texto clásico de Mijail Bajtin (2008) y el más reciente de Franco Moretti (1987), en el que este crítico insiste en la relevancia que tuvo este género en la implantación de la juventud, en la cultura moderna occidental, como el periodo más significativo de la vida -Moretti (1987: 3) refiere, entre muchos otros, a los jóvenes Rastignac, Julien Sorel o Frédéric Moreau. José Luis de Diego (1998) se ha ocupado de analizar la presencia de ese género en la literatura argentina, una presencia que se iniciaría con Las divertidas aventuras del nieto de Juan Moreira, continuaría con Don Segundo Sombra, El juguete rabioso y, más adelante, La traición de Rita Hayworth, y alcanzaría un primer cierre en Flores robadas en los jardines de Quilmes y Respiración artificial. Me interesa proponer que existen al menos dos textos previos que, pese a su índole autobiográfica, bien pueden pensarse como novelas de formación: Juvenilia, de Miguel Cané y, antes, Recuerdos de provincia. De Diego, además, establece una caracterización del género que, aunque preliminar, es muy útil para deslindar sus rasgos más salientes: “Digamos entonces que se trata de un tipo de novela: a) cuyo origen se relaciona directamente con el programa ideológico de la Ilustración alemana y el clasicismo de Weimar; b) en la que se narra el desarrollo de un personaje - generalmente un joven- a través de sucesivas experiencias que van afectando su posición ante sí mismo, y ante el mundo y las cosas; por ende, el héroe se transforma en un principio estructurante de la obra; c) que cumple -o busca cumplir-una función propedéutica, ya sea positiva -modelo a imitar- o negativa -modelo a rechazar-, independientemente de la mayor o menor presencia de la voz autoral; d) a cuya caracterización pueden ser asociados textos de diferentes épocas y de diversa procedencia; e) que no cumple un papel fijo en los debates ideológicos, ya que su grado de reformismo o conservadurismo depende de los modos de relacionarse los textos con los contextos históricos de producción" (1998: 7). Por lo demás, si consideramos a Recuerdos de provincia como una suerte de Bildungsroman, habría que precisar que sería una Bildungsroman del tipo que más le interesa a Bajtin (quien se preocupa por la importancia de este género "en la historia del realismo"): novelas en las que "el desarrollo no viene a ser su asunto particular. El hombre se transforma junto con el mundo, refleja en sí el desarrollo histórico del mundo. El hombre no se ubica dentro de una época, sino sobre el límite entre dos épocas, en el punto de transición entre ambas. La transición se da en el hombre y a través del hombre" (2008: 211). En efecto, y como bien lo han señalo Adolfo Prieto y, años después, Adriana Rodríguez Pérsico, la formación del héroe de Recuerdos de provincia se realiza en -y refleja- la transición entre el viejo orden colonial y el nuevo orden (Prieto, 1982: 50): "El sujeto autobiográfico anuda todos los tiempos, todos los espacios y todas las culturas” (Rodríguez Pérsico, 1992: 69).

16 "En varios trabajos Rancière examina cómo el realismo novelesco de escritores como Gustave Flaubert, Honoré de Balzac y Victor Hugo presta atención a un mundo de actores insignificantes y objetos de la vida cotidiana, que adquieren así un nuevo nivel de visibilidad social y de valor simbólico" (Ross, 2010: 157, traducción mía). Algunos de los materiales de los que está hecho Recuerdos de provincia son de la misma índole que los mencionados en esta cita a propósito de las consideraciones de Rancière sobre algunos novelistas fundamentales del XIX. La idea de que la literatura -y más específicamente la novela- se ocupó de narrar vidas insignificantes, vidas sin derecho a la gloria o a la fama, vidas cotidianas, fue adelantada por Michel Foucault en "La vida de los hombres infames", publicado originalmente en francés 
implica, por tanto, no solo advertir que en este libro hay algo del orden de la trama que lo emparienta con una entonación importantísima de la novela -la Bildungsroman-, sino además a que en él se verifica "esa caída del sistema de coerciones y jerarquías que constituía el régimen representacional del arte" que en la novela del siglo XIX es especialmente evidente. En este sentido, propongo leer esa censura de Alberdi a Recuerdos de provincia, y con la suya la de muchos otros, como expresión de la aprensión que generó un texto que desobedecía ordenamientos y convenciones. Una censura que hace foco, entre otras cuestiones, en el hecho de que Sarmiento, al escribir y publicar su autobiografía (su proto-novela), habría transgredido las jerarquías que determinaban qué era digno, o no, para ingresar "en el reino del arte". No por nada Sarmiento señaló que con su libro había "traspasado todo límite". ${ }^{17} \mathrm{La}$ escritura osada de Sarmiento es, a mediados del siglo XIX, una de las que, en América del Sur, está en mejor sintonía con su siglo: es decir, con un nuevo modo de entender qué es la literatura. Una escritura en la que, por ejemplo, se borronean los límites entre creación artística y vida anónima. ${ }^{18}$ La reprobación y la alarma de Alberdi y de otros ante Recuerdos de provincia son, entonces, entre otras cosas, evidencia de una dificultad o de una negación para percibir o aceptar esa cualidad contemporánea de la escritura -de la literatura- de Sarmiento.

en 1977. Allí anota que desde el siglo XVII “la ficción ha reemplazado desde entonces lo fabuloso; la novela se liberó de lo fantástico y no se desarrollará más que liberándose totalmente de sus ataduras. La literatura forma parte, por tanto, de este gran sistema de coacción que en Occidente ha obligado a lo cotidiano a pasar al orden del discurso" (2008: 173). 17 Sarmiento le mandó una carta a su amigo Manuel Montt en la que afirma: “Adjunto a usted un ejemplar de Recuerdos de provincia. Ahora que está impreso y lo he leído con calma empiezo a creer que he traspasado todos los límites de la indulgencia de los que hayan de leerlo, que no serán por ahora sino mis amigos aquí, porque toda la edición la echaré a la otra banda, donde la crítica me incensa con humos que no pueden ya subir de punto" (Sarmiento, 1988: 144, énfasis mío).

18 Sobre otras cuestiones que también darían cuenta de esa sintonía (por ejemplo, con el melodrama), veáse Contreras (2012). 


\section{Bibliografía}

"Alberdi, J. B. (2005). Cartas sobre la prensa y la política militante en la República Argentina (Cartas quillotanas). En Alberdi, J. B. y Sarmiento, D. F., La gran polémica nacional. Edición y prólogo de Lucila Pagliai. Buenos Aires: Leviatán.

" Altamirano, C. y Sarlo, B. (1997). “Una vida ejemplar: la estrategia de Recuerdos de provincia”. En Ensayos argentinos. Buenos Aires, Ariel.

»Bajtin, M. (2008). "La novela de educación y su importancia en la historia del realismo”. En Estética de la creación verbal. México: Siglo XXI.

»Barrenechea, A. M. (1988). Carta de Sarmiento a Rugendas. Nueva Revista de Filología Hispánica, vol. XXXVI, $\mathrm{n}^{\circ}$ 1, pp. 407-416.

»Butler, J. (2009). Dar cuenta de sí mismo. Violencia, ética y responsabilidad. Buenos Aires: Amorrortu.

»Campobassi, J. (1975). Sarmiento y su época. Dos volúmenes. Buenos Aires: Losada.

"Casper, Scott E. (1999). Constructing American Lives: Biography and Culture in Nineteenth-Century America. Chapel Hill: University of North Carolina Press.

"Contreras, S. (2012). “Facundo: la forma de la narración”. En Amante, A. (dir. del volumen) y Jitrik, N. (dir. de la obra), Historia crítica de la Literatura argentina, vol. 4: Sarmiento. Buenos Aires: Emecé, pp. 67-94.

»De Diego, J. L. (1998 y 2000). La novela de aprendizaje en Argentina (1 $1^{\underline{a}}$ parte y $2^{\underline{a}}$ parte). Orbis Tertius, $n^{\circ} 3(6)$ y n $^{\circ} 4$ (7).

»Echeverría, E. (1900). “Cartas a Juan Bautista Alberdi”. En Alberdi, J. B., Escritos póstumos, tomo XV, "Memorias y documentos". Buenos Aires: Imprenta Juan Bautista Alberdi, pp. 772-796.

" Fontana, P. (2010). "Es de la boca de un viejo / de ande salen las verdades. Memoria, vejez y usos del pasado". En Jitrik, N. (dir. de la colección) y Alejandra Laera (dir. del volumen), Historia Crítica de la Literatura Argentina, vol. 3: El brote de los géneros. Buenos Aires: Emecé, pp. 61-93.

»Fontana, P. (2015). Sarmiento y Alberdi ante la autobiografía: la vanidad y la culpa. En A Contracorriente, vol. $12, \mathrm{n}^{\circ}$ 3. Disponible en https://acontracorriente. chass.ncsu.edu/index.php/acontracorriente/article/view/1285

» Foucault, M. (2008). La vida de los hombres infames. Buenos Aires: Caronte.

» Gálvez, M. (1962). Vida de Sarmiento. En Biografías completas, tomo II. Buenos Aires: Emecé.

» Genette, G. (1989). Figuras III. Barcelona: Lumen.

" Gossman, L. (mayo, 2003). Anecdote and History. History and Theory, vol. 42, $\mathrm{n}^{\circ}$ 2, pp. 143-168.

" Gusdorf, G. (1991). Condiciones y límites de la autobiografía. Suplementos Anthropos, $\mathrm{n}^{\circ}$ 29: La autobiografía y sus problemas teóricos. Estudios e investigación documental, pp. 9-18.

» Jitrik, N. (1997). “Autobiografía, biografía y fuerte desplazamiento hacia la narración: Sarmiento en el origen de una literatura”. En Ejemplo de la familia. Bue- 
nos Aires: Eudeba, pp. 11-24.

» Lotman, I. (2006). La biografía literaria en el contexto histórico-cultural (la correlación tipológica entre el texto y la personalidad del autor). Alicante: Biblioteca Virtual Miguel de Cervantes.

"Loureiro, Á. (2006). “Autobiografía: el rehén singular y la oreja invisible”. En Rusotto, M. (Comp. y Ed.), La ansiedad autorial: formación de la autoría femenina en América Latina. Venezuela: Equinoccio-Universidad Simón Bolívar, pp. 19-39.

»Lugones, L. (1911). Historia de Sarmiento. Buenos Aires: Consejo Nacional de Educación.

"Mansilla, L. V. (2001). “El famoso fusilamiento del caballo”. En Los siete platos de arroz con leche. Prólogo de Claudia Roman. Barcelona: Sol 90.

"Moretti, F. (1987). The Way of the World: The Bildungsroman in European Culture. Londres: Verso.

»Pas, H. (2015). El don de los Recuerdos. Domingo Faustino Sarmiento y la autobiografía como publicidad. Caracol, n 10, pp. 38-59.

»Piglia, R. (1998). Sarmiento escritor. Filología, año XXXI, no 1-2, pp. 19-34.

»Prieto, A. (1982). La literatura autobiográfica argentina. Buenos Aires: Centro Editor de América Latina.

» Rodríguez Pérsico, A. (1992). Un huracán llamado progreso. Utopía y autobiografía en Alberdi y Sarmiento. Washington: OEA-Interamer.

»Rojas, R. (1945). El profeta de la Pampa. Vida de Sarmiento. Buenos Aires: Losada.

»Rancière, J. (2006). “La política de la estética”. Otra Parte, $n^{\circ} 9$ (cuaderno). Disponible en http://www.caimanbarbudo.cu/articulos/2011/o7/la-politica-de-laestetica/

»Roman, C. (2010). La prensa satírica argentina del siglo XIX: palabras e imágenes, tesis de doctorado, Facultad de Filosofía y Letras (UBA). Disponible en http:// repositorio.filo.uba.ar/handle/filodigital/1613

» Ross, T. (2010). “Image, montage”. En Deranty, Jean-Philippe (Ed.), Jaccques Roncière. Key concepts (pp. 151-177). Durham: Acumen.

"Sarmiento, D. F. (1885). Mi defensa. En Obras completas, tomo III, Santiago de Chile: Imprenta Gutenberg.

»Sarmiento, D. F. (1998). La correspondencia de Sarmiento. Primera serie: Tomo I: años 1838-1854. Córdoba: Comisión Provincial de Homenaje a Domingo Faustino Sarmiento.

"Sarmiento, D. F. (2001). Recuerdos de provincia. Barcelona: Sol 90.

»Starobinski, J. (2008). La relación crítica. Buenos Aires: Nueva Visión.

»Williams Bunkley, A. (1966). Vida de Sarmiento. Buenos Aires: Eudeba. 